\title{
Microcomputer software to facilitate costing in pathology laboratories
}

\author{
J A STILWELL, F P WOODFORD
}

From the Health Services Research Unit, Institute for Management Research and Development, University of Warwick, Coventry, and Department of Health and Social Security (Russell Square), London

SUMMARY A software program is described which will enable laboratory managers to calculate, for their laboratory over a 12 month period, the cost of each test or investigation and of components of that cost. These comprise the costs of direct labour, consumables, equipment maintenance and depreciation; allocated costs of intermediate operations - for example, specimen procurement, reception, and data processing; and apportioned indirect costs such as senior staff time as well as external overheads such as telephone charges, rent, and rates. Total annual expenditure on each type of test is also calculated.

The principles on which the program is based are discussed. Considered in particular, are the problems of apportioning indirect costs (which are considerable in clinical laboratory work) over different test costs, and the merits of different ways of estimating the amount or fraction of staff members' time spent on each kind of test. The computer program is Crown copyright but is available under licence from one of us (JAS).

The benefits of costing pathology laboratory work have been described previously, ${ }^{1}$ and are gaining more prominence with the application of the results to the analysis of resource consumption by clinical teams in various specialties. ${ }^{2}$ Sophisticated costing methods have recently been described, ${ }^{3}$ but problems remain. Two of these problems are discussed here, with our suggested solutions, as part of the description of a microcomputer program to aid the laboratory cost analyst.

This program displays the calculated average total cost for each kind of test performed in a single laboratory during a particular year. Furthermore, it displays this cost broken down into six components, thus meeting the criticisms ${ }^{34}$ of previous costing methods that aggregating all cost components into a single cost per test jettisons important management information.

\section{Direct and indirect costs}

The method, like all previous laboratory costing methods, starts with the assumption that the output of the laboratory to be costed is test reports. By analogy with manufacturing production, direct costs are

Views expressed are not to be taken as reflecting Department of Health and Social Security policy.

Accepted for publication 13 January 1987 defined as those necessarily and exclusively associated with investigating the specimen and reporting the test result ${ }^{5}$; indirect costs are all others-that is, those not directly associated with the production of any particular test report.

A major dilemma in laboratory costing continues to be how to apportion indirect costs over individual test costs. Indeed, confusion still reigns over how to distinguish different types of indirect cost and whether it is actually appropriate to include all of them in charges to clinical budgets. We describe here a method for defining different kinds of indirect cost and for apportioning each kind differently, if desired, on a rational basis.

The program prints the total cost of performing one of each kind of test provided by a laboratory during the past year. This test cost is broken down into six components: (i) direct ("hands-on") labour; (ii) reagents and other consumables; (iii) equipment maintenance (plus equipment depreciation if desired); (iv) allocated costs of intermediate operations-for example, specimen reception and preparation, data processing, and production of reports; ( $v$ ) apportioned indirect costs (physical overheads and, quantitatively more important, that portion of staff time which is unrelated to the production of test results); and (vi) allocated residual costs - that is, labour and consumables not otherwise accounted for. These sep- 
arate listings allow the user to select at will various components of the cost either for comparison with other laboratories or for inclusion or exclusion in calculating charges to clients of the laboratory. Costs of direct labour and consumables are the most pertinent ones to use in comparing the costs of different methods of performing a given test or investigation; while the consequences of loading or not loading research and development costs on to a test charge may be readily obtained by repeating the cost analysis with a suitable change of parameters.

Broughton and Hogan defined direct test costs as those necessarily and easily associated with performing the test or investigation and reporting the result. ${ }^{4}$ We do the same. Indirect costs were regarded as all other costs incurred by the laboratory and were obtained by subtracting the calculated direct costs of all tests performed from the total laboratory costs. Broughton and Hogan avoided loading this aggregate measure of indirect costs on to each test cost because they considered that the conventional way of doing this - in proportion to direct costs-was illogical and misleading; there seemed to be no rational way of apportioning indirect costs over the various types of test. Instead, they calculated an average "handling charge per request" by dividing the total indirect costs by the total number of requests. (In the United Kingdom one "request" usually accompanies each specimen and may require one or several tests to be performed.) They argued that indirect costs are more likely to be proportional to the number of requests than to any other parameter. We prefer to subdivide indirect costs into categories and apportion each category over test costs in the most appropriate way rather than spreading the heterogeneous aggregate equally over all client requests. The computer programme we describe below allows the user to specify a different apportionment basis for each kind of indirect cost.

The philosophy of our costing method was developed under World Health Organisation auspices in a programme aimed at enabling laboratories to compare their costs internationally whether they formed part of a public or a private health care system. ${ }^{6}$ As commercial laboratories commonly charge for each test (or specified group of tests) the costing method described here derives a cost for each test rather than distinguishing between requests and tests. It includes all types of cost, whether explicitly paid for or notfor example, rent and rates in a public health care system. As the method evolved, several categories of indirect cost emerged, each with its appropriate apportionment basis (table).

The first and most familiar kind of indirect cost is the external overhead, which consists of charges to the laboratory, if any, from the host institution or
Table Apportionment bases for indirect costs

\begin{tabular}{|c|c|c|}
\hline Code & $\begin{array}{l}\text { Basis of } \\
\text { apportionment }\end{array}$ & Examples \\
\hline 1 & Space & $\begin{array}{l}\text { Rent, rates, heating, lighting, } \\
\text { cleaning }\end{array}$ \\
\hline 2 & Staff members & $\begin{array}{l}\text { Personnel management, staff } \\
\text { welfare }\end{array}$ \\
\hline 3 & Equipment & $\begin{array}{l}\text { Insurance, equipment development } \\
\text { costs }\end{array}$ \\
\hline 4 & Number of tests & $\begin{array}{l}\text { Postage, telephone, messengers, } \\
\text { transport }\end{array}$ \\
\hline 5 & Test direct cost & $\begin{array}{l}\text { Accountants' fees, bank interest, } \\
\text { mortgage fees, management time } \\
\text { aimed at maximising profit or } \\
\text { efficiency }\end{array}$ \\
\hline 6 & Test type & $\begin{array}{l}\text { All others which cannot be } \\
\text { associated with production of } \\
\text { particular test results and reports }\end{array}$ \\
\hline 7 & $\begin{array}{l}\text { Test direct labour } \\
\text { cost }\end{array}$ & Residual labour cost at workstations \\
\hline 8 & $\begin{array}{l}\text { Test direct } \\
\text { consumables cost }\end{array}$ & Residual consumables costs \\
\hline
\end{tabular}

local authority. Many of these-for example, rent, $\stackrel{0}{C}$ rates, and heating costs - are proportional to space os occupied and may logically be apportioned to indi- $\vec{\bullet}$ vidual tests in proportion to the space the relevant $\stackrel{\infty}{\infty}$ workstations occupy. Others-for example, postage * and telephone costs-are not, and are probably best apportioned over tests in proportion to the number of each kind of test performed.

A second kind of indirect cost is the cost of staff time devoted to general duties unconnected with the $\varrho$ production of particular test results-for example, $\overrightarrow{\vec{O}}$ training, research, and administration. These costs 3 need to be apportioned over tests in a rather more arbitrary way (either by "test number" or by "test type", discussed below). Each staff member will be able to estimate without difficulty roughly how much? of his or her time is spent on each type of general 3 duty.

A third kind of indirect cost is supervision, and each staff member is asked to estimate how much of 0 his or her time is devoted to supervision as opposed to hands-on work. The staff who produce test results are $\frac{7}{0}$ supervised. Supervisory costs are therefore most appropriately apportioned over the people supervised $N$ in proportion to the total direct time the latter spend $N$ on each kind of test. Alternatively, it may be argued $N$ that the supervisor spends about the same amount of ${ }^{\mathrm{C}}$ time on supervising each test type in his or her section, irrespective of how many such tests are per- $\stackrel{0}{\square}$ formed. The program allows the user to choose an apportionment basis to fit either of these cases: either in proportion to direct labour costs (case 1 above) or equally over test types (case 2).

The fourth kind of indirect cost is "residual" labour-that is, what remains when the time spent on $\stackrel{D}{D}$ 
each test multiplied by the number of tests done is subtracted from the working time available (the total working hours less general duties and supervisory time). Residual consumables costs are calculated similarly and represent consumables wasted. The program calculates a figure for residual labour at each workstation and section in the laboratory, which acts as a check on the estimates of time entered for each test (and other duties) and can also indicate where there is spare capacity at particular locations.

Broughton and Hogan calculated the total indirect costs as the difference between direct and total costs, and their indirect costs therefore encompassed supervisory, general duties, and residual costs. (External overheads were omitted since these authors were concerned solely with National Health Service laboratories in the United Kingdom, which at that time were not charged for such overheads.) These indirect costs were apportioned equally over all requests on the grounds that many of them-for example, specimen sorting, serum separation-were proportional to the number of requests. Although we, too, would allocate this kind of indirect cost (which we classify as intermediate) by number of tests, most indirect costs are not proportional to the number of tests or requests. In view of the magnitude of such indirect costs $^{5}$ (as much as $60-80 \%$ of the total ${ }^{4}$ ) we believe that it is worth taking the trouble to attribute them more accurately to specific tests where possible.

Thus residual costs-representing mostly "waiting time" at bench level-should almost certainly be associated with the tests performed at the relevant workstation and either allocated in proportion to the direct labour cost of each test there or allocated equally to each test type performed at that workstation. Supervisory costs can also be readily associated with particular tests in the workstation, section, or subdepartment supervised. Serum separation costs should be associated with serum assays only, not those in blood, urine, or cerebrospinal fluid. Some general duties can also be associated with specific tests or groups of tests-for example, radiation protection duties with investigations using radioisotopes.

For the general duties which cannot be associated with the production of particular tests-of which there are many, ranging from clinical liaison, teaching, and clinical practice to committee and other hospital work - there seems to be no greater logic in apportioning them equally over requests than equally over tests. Since these costs are independent of the number of requests fulfilled or tests performed we believe that they should not be allocated in proportion to numbers of either, but equally over all test types.

The computer program allows all these indirect costs to be apportioned separately and in different ways. This is conducive to greater accuracy of costing, allows the different elements of indirect test costs to be compared between laboratories, and provides management information useful in organising or reorganising work distribution within the laboratory.

\section{Timing procedures}

A second problem in costing a test is how to estimate the direct labour cost in a way that is fair to the client and to laboratory staff. Ideally, one would like to be able to enter into the costing program the average amount of time a benchworker takes to complete the work on any particular test. It is well known, however, that this time varies considerably, even for one individual, between the extremes at particularly busy and particularly slack periods ${ }^{4}$ (also Leijten JF, personal communication). Nobody likes to be timed by an observer, and most people behave differently from usual when under observation.

The computerised costing procedure can bypass this difficulty if the residual labour cost is allocated in proportion to direct labour cost as described in the previous section. An approximate hands-on time for each test can be assigned to the test (or else the time given in the Canadian workload unit schedule may be used $^{7}$ ); the residual labour cost is then apportioned over the relevant tests in proportion to the direct labour cost (table). This is tantamount to stretching all the hands-on time of each staff member to fill the productive working time available. The manoeuvre is equivalent to that employed in the Arthur Young system described by Tarbit, ${ }^{3}$ in which an enhancing factor is used to the same end: the total direct time spent on test production is calculated from estimates of the average time needed for each type of test multiplied by the number of tests performed, and then each element of direct time is multiplied by an enhancing factor which brings the whole up to $100 \%$ of the working time available.

The advantage of the system described here is that each estimated direct time does not have to be multiplied by the same factor to fill the total number of working hours. The system will already have made allowance for time spent on any general duties and supervision, so it is only the hands-on hours that are filled. Supervisory costs are handled by the program in the same way: they are spread over the staff members supervised, and thence over the tests, in proportion to the total hands-on time spent on each test.

A further facility of the costing program is that if the cost analyst decides after the first run that the residual costs should be spread over the tests differently-for example, by test type instead of according to direct labour costs- he is free to specify a different basis of apportionment. The table shows 


\section{PATHOLOGY DEPARTMENT COSTING SYSTEM}

Enter the module required:
(1) System description
(3) Staff input
(5) Staff deletion
(7) Equipment input/edit
(9) Tests data amendment
(11) Enter General Duties
(13) Ind Costs Apportionment
(15) Residual Costs Allocation
(17) SELECT VIEW MENU
(19) Analyse and print costs
(20) End

Fig 1 Main menu of program.

the eight possible apportionment bases in the program.

\section{The costing program}

The programs use as building blocks elements that are readily recognisable by laboratory staff. The data input, manipulation, and analysis programs are called from a main menu (fig 1), which appears on the screen at the start of the procedure. Two other options can be called from this menu-a view menu and a print menu-which enable the cost analyst to check the data entered.

The laboratory "system" to be costed is first defined in module 1 in response to screen prompts asking for the system to be described by physical locations arranged hierarchically. These are DEPARTMENTS (for example, clinical chemistry), SECTIONS (for example, radioimmunoassay), and WORKSTATIONS (for example, multiple pipetting station). TESTS are listed by name within each workstation. Up to five departments can be accommodated, each containing up to four sections. Fig 2 shows a simple imaginary system.
(2) System amendment

(4) Staff amendment

(6) Areas module

(8) Tests data input

(10) Intermediate workstations

(12) Enter Other Indirect Costs

(14) Delete Indirect Costs

(16) Enter Consumables Expenditure

(18) SELECT PRINT MENU
The second module allows amendments to be made to the description of the system in case of error or subsequent changes.

The third module, Staff input, is one of the two main data entry modules (the other being Tests data input). Three types of data are entered for each member of staff: (i) facts about pay, paid hours or sessions, and holidays; (ii) data about where in the system the member of staff works and how long, and how much of that time is spent on general duties (up to three kinds) such as quality control, research, or health and safety; (iii) how much of his or her time is spent on direct or supervisory work on particular tests or at specified workstations, sections, or whole departments. The number of different tests or locations that can be specified for the third kind of data is unlimited. Fig 3 shows data on the two staff members in the imaginary system and the summary of data on supervision which the program displays.

The Areas module allows the operator to input the physical areas of the sections and workstations defined in module 1 . This facility is optional, being needed only if indirect costs such as heating and lighting are to be allocated on the basis of occupied space.

YOUR SYSTEM DESCRIPTION IS AS FOLLOWS

DEPARTMENT NO 1 CLINCHEM

SECT NO 1 ROUTINE

WORKSTATION NO 1 AUTOANALYSER

WORKSTATION NO 2 PREPARATORY

\section{THE FILE ENTRY NUMBERS OF THE ABOVE ARE AS FOLLOWS}

$\begin{array}{ll}100 & \text { CLINCHEM } \\ 110 & \text { ROUTINE } \\ 111 & \text { AUTOANALYSER } \\ 112 & \text { PREPARATORY }\end{array}$

Fig 2 Printout of system description (a minimal imaginary laboratory system, for illustrative purposes). 
NUMBER OF STAFF: 2

\begin{tabular}{|c|c|c|c|c|}
\hline \multirow[t]{3}{*}{ STAFF NO 1} & PARAMETER & REFERENCE & ENTRY & \\
\hline & $\begin{array}{l}\text { Works Number } \\
\text { Staff Type } \\
\text { Grade } \\
\text { Gross cost } \\
\text { Hours per week } \\
\text { Days holiday } \\
\text { General duty } 1 \\
\text { General duty } 2 \\
\text { General duty } 3\end{array}$ & $\begin{array}{l}1 \\
2 \\
3 \\
4 \\
5 \\
6 \\
7 \\
8 \\
9\end{array}$ & $\begin{array}{r}10 \\
2 \\
4 \\
10000 \\
40 \\
25 \\
0 \\
0 \\
0\end{array}$ & \\
\hline & \multicolumn{2}{|c|}{$\begin{array}{c}\text { WORK LOCATION REFERENCE } \\
111 \\
112\end{array}$} & $\begin{array}{l}\text { SUPERVISION } \\
0 \\
0\end{array}$ & $\begin{array}{l}\text { HANDS-ON } \\
25 \\
15\end{array}$ \\
\hline \multirow[t]{3}{*}{ STAFF NO 2} & PARAMETER & REFERENCE & ENTRY & \\
\hline & $\begin{array}{l}\text { Works Number } \\
\text { Staff Type } \\
\text { Grade } \\
\text { Gross cost } \\
\text { Hours per week } \\
\text { Days holiday } \\
\text { General duty } 1 \\
\text { General duty } 2 \\
\text { General duty } 3\end{array}$ & $\begin{array}{l}1 \\
2 \\
3 \\
4 \\
5 \\
6 \\
7 \\
8 \\
9\end{array}$ & $\begin{array}{r}20 \\
1 \\
1 \\
16000 \\
40 \\
30 \\
30 \\
0 \\
0\end{array}$ & \\
\hline & WORK L & DN REFERENCE & $\begin{array}{l}\text { SUPERVISION } \\
8 \\
2\end{array}$ & $\begin{array}{l}\text { HANDS-ON } \\
0 \\
0\end{array}$ \\
\hline STAFF NUMBER & LOCATION & \multicolumn{2}{|c|}{ HOURS PER WEEK SUPERVISION } & \\
\hline $\begin{array}{l}\text { STAFF NUMBER } 10 \\
20 \\
20\end{array}$ & \multicolumn{3}{|c|}{$\begin{array}{cc}\text { CARRIES OUT NO SUPERVISION } \\
111 & 8 \\
112 & 2\end{array}$} & \\
\hline
\end{tabular}

Fig 3 Staff data, illustrative example. Staff member 1 has hands-on work only; staff member 2 spends 30 hours a week on general duties (management) and the rest on supervision at both workstations. Lower part of figure details amount of supervision by each member of staff at each location.

It has not been used in the illustrative example.

Module 7, Equipment entry, allows input of the capital inventory. For each item of equipment the cost analyst enters the annual maintenance cost and, if capital depreciation costs are to form part of the calculation, the equipment's capital value and expected lifetime. The program will then calculate an annuitised charge using the discount rate of $5 \%$ recommended by the United Kingdom Treasury and this cost will subsequently be spread over those tests which use the equipment. This module is included because, although the National Health Service operates on recurrent expenditure accounting, it is evident that costs which do not include a capital element remain partial (even though on average the capital costs of laboratory tests amount to only $7-12 \%$ of the whole $^{1}$ ) and, where it is necessary to make charges to the private sector, will result in under-recovery. If the equipment is leased the leasing charge is added to the maintenance costs, if any, and the equipment's capital value is, of course, omitted.

Modules 8 and 9 are the main Test data entry and Amendment modules. For each test performed, the following items are entered:

Number of workstation where test is produced

Annual number performed

Number of batches per month (if applicable)

Set up time per batch (optional)

Equipment time per test

Hands-on time per test (which may be different from equipment time)

Consumables cost, per batch (cost of set up) and per test

Equipment used (up to three items). 


$\begin{array}{ccl}\text { Columns are as follows: } & 1 & \text { Workstation number } \\ & 2 & \text { Annual number } \\ 3 & \text { Batches per month } \\ 4 & \text { Set up time per batch } \\ 5 & \text { Equipment time per test } \\ 6 & \text { Hands-on time per test } \\ 7 & \text { Consumables cost for set up } \\ 8 & \text { Consumables cost per test } \\ 9-11 & \text { Equipment number(s) }\end{array}$

YOU HAVE 2 TESTS ON FILE

$\begin{array}{lll}\text { REF NUMBER } & \text { TEST NAME } & \text { COMMENTS } \\ 1 & \text { PROFILE } & 16 \text { TESTS } \\ 2 & \text { LFT } & \text { LIVER FUNCTION TESTS }\end{array}$

$\begin{array}{lcccccccccc}\text { REF } & & & & & & & & & & \\ \text { NO } & 1 & 2 & 3 & 4 & 5 & 6 & 7 & 8 & 9 & 10 \\ 1 & 111 & 16000 & 999 & 0.00 & 3.00 & 3.00 & 0.00 & 0.40 & 1 & 0 \\ 2 & 111 & 4000 & 999 & 0.00 & 2.00 & 1.00 & 0.00 & 0.40 & 1 & 0\end{array}$

Fig 4 Tests data. (In this model there are only two tests, both serum assays at the same workstation. Neither is performed in infrequent batches. They are assigned the same equipment time and consumables costs but different hands-on times.

$\begin{array}{lllll}\text { COL REF: } & 1 & 2 & 3 & 4 \\ & \text { NAME } & \text { COST } & \text { LIFE } & \text { MAINTENANCE } \\ 1 & \text { SMAC } & 0 & 1 & 5000 \\ 2 & \text { CENTRIFUGE } & 0 & 1 & 200\end{array}$

Fig 5 Equipment data. SMAC is used at workstation 111 for both tests and the centrifuge at intermediate workstation 112. When capital depreciation is not to be included in cost analysis zero is entered in column 2; life expectancy (column 3) is an arbitrary figure of no importance. Program adds maintenance costs to any capital depreciation costs to yield total equipment costs.

There is also a comments field, which serves as an aide memoire.

The work entailed in calculating separately the consumables cost of a test cannot be avoided. If reagents were all specific to tests a short cut using computerised invoice data might be possible, but they are not. In any costing system it is therefore necessary to calculate the amount (and hence cost) of various consumables used to calibrate the equipment, quality control the batch, and produce each test result.

Fig 4 shows the data for the two tests performed at workstation 111 in the illustrative example, and fig 5 shows the associated equipment data.

Some workstations do not produce test results but house some activity which feeds another workstation (such as centrifuging, pipetting, or wax blocking). Such workstations are identified, together with the workstations and tests over which their costs must be spread, in module 10 . In the illustrative example serum separation is performed at workstation 112 and its costs are allocated to both the serum assays performed at workstation 111 (fig 6, top).
Workstation number 112 allocated to: Departments, sections and workstations numbers 111 Associated equipment: 2

Indirect cost 201,12000 per year, type 6 apportioned to:

Departments, sections and workstations numbers 100

\section{ALLOCATION RULES \\ RESIDUAL LABOUR 7 \\ RESIDUAL CONSUMABLES 8 \\ SECTION COSTS 6 \\ DEPARTMENT COSTS 6}

Fig 6 Top: allocation of costs of intermediate (preparatory) workstation 112 to the tests performed at workstation 111. Middle: Apportionment codes and ranges for indirect costs (in this case only one general duty, staff works no 20, "management"). Bottom: allocation rules assigned for residual costs $(7=$ direct labour cost, $8=$ direct consumables cost, $6=$ test type). 
Modules 11 and 12 are the programs which ask for the apportionment rules for indirect costs. Module 11 deals with General Duties, and the user is presented with the names and annual costs of the general duties derived from the staff file. Module 12 asks for the names of and the annual expenditure on other indirect costs such as building maintenance or charges for transport of specimens. It is here that the special characteristics of the costing system become apparent. The user is asked, first, to choose a rule for the apportionment of each indirect cost, and then to define a range of the laboratory elements (tests, workstations, sections, or departments) over which the cost is to be spread. An example will make this clear. An indirect cost (general duty) might be the time per week spent by a staff member on radiation protection training. This would have been entered in module 3. Module 11 will calculate the annual wages bill equivalent of this activity and will prompt the user to specify the rule by which this cost should be apportioned and over which tests. The rules available at this stage are: space, staff, equipment, test number, test direct cost, and test type. The appropriate rule in this case would be staff (computationally, proportional to staff time), so that a test with, say, twice the labour content of another would have twice as much radiation safety cost charged to it. The range of tests over which the costs should be spread would be those using radioisotopes, and the program allows the user to specify them individually or to name the appropriate workstation or section if this is simpler.

Fig 6 (middle block) shows the apportionment basis for the sole indirect cost identified in the illustrative example - namely, $£ 12000$ worth of general duties (management) of the senior staff member. The chosen basis is 6 (test type)-that is, the costs are spread equally over the two test types.

Indirect cost data can be edited and modified if necessary in the next two modules.

All published studies on pathology costs emphasise that residual costs constitute a large proportion of the whole: $50 \%$ of consumables costs ${ }^{1}$ and at least $40 \%$ of direct labour costs (derivable from the experience of the Canadian workload system team that 35 units/hour is a reasonable expectation of "resultproduction" staff). These residual costs are the costs of consumables purchased but "wasted" and the costs of labour when not producing test results. The costing system described here has built into it an estimate of labour residual costs for it contains data on how many hours are worked at each workstation and also how long the tests performed at each workstation should take. The residual labour cost is therefore derived by subtraction. Module 16 asks for the total expenditure on consumables, and the system then possesses analogous information to calculate residual consumables cost-but, in the case of consumables, costs overall and not by workstation.

As with indirect costs, rules can be chosen for the apportionment of residual costs (module 15). Besides the six available for indirect costs, two more are on offer for residual costs: test direct labour cost and test direct consumables cost.

Fig 6 (bottom) shows that the apportionment basis chosen in the illustrative example for residual labour is 7 (test direct labour cost); for residual consumables it is $\mathbf{8}$ (test direct consumables cost); and for any section or departmental costs-for example, the director's secretarial costs, not present in this case-it would be 6 (test type).

After all the data have been entered selection of module 19 will start the cost analysis. The output (fig 7) is as follows:

1 List of equipment, with costs per minute in use.

2 Cost of equipment in use at intermediate workstations.

3 Cost of unused equipment.

4 List of indirect costs, separately identified (for example, each general duty for each staff member, as well as all other indirect costs specified), each with its cost and the apportionment rule selected for it.

5 Table of test costs, with the following data for each test:

a Name.

b Comment.

c Annual number.

d Direct labour cost.

e Direct consumables cost.

f Equipment cost.

g Total direct cost (sum of $\mathrm{d}-\mathrm{f}$ ).

h Allocated intermediate workstation cost.

i Apportioned indirect cost.

j Allocated supervisory and residual cost.

k Total indirect cost (sum of $h-j)$.

1 Total cost (sum of $\mathbf{g}$ and $\mathbf{k}$ ).

$\mathrm{m}$ Total recurrent expenditure on that test (1 minus $f$, times $c$ ), also as a percentage of all recurrent expenditure.

$n$ Total capital expenditure on that test (f times c), also as a percentage of all capital expenditure.

o Total expenditure on that test (m plus $n$ ), also as a percentage of all test expenditure.

6 Annual cost of whole system

7 Departmental labour report.

8 Section labour report.

9 Workstation labour report.

Tabulations 7-9 contain the following information for each department, section and workstation:

Total tests (number)

Total labour cost 
EQUIPMENT

COST PER MINUTE IN USE

SMAC

0.089

ANNUAL COST OF CENTRIFUGE AT INTERMEDIATE WORKSTATION IS 200

ANNUAL COST OF UNUSED EQUIPMENT 0

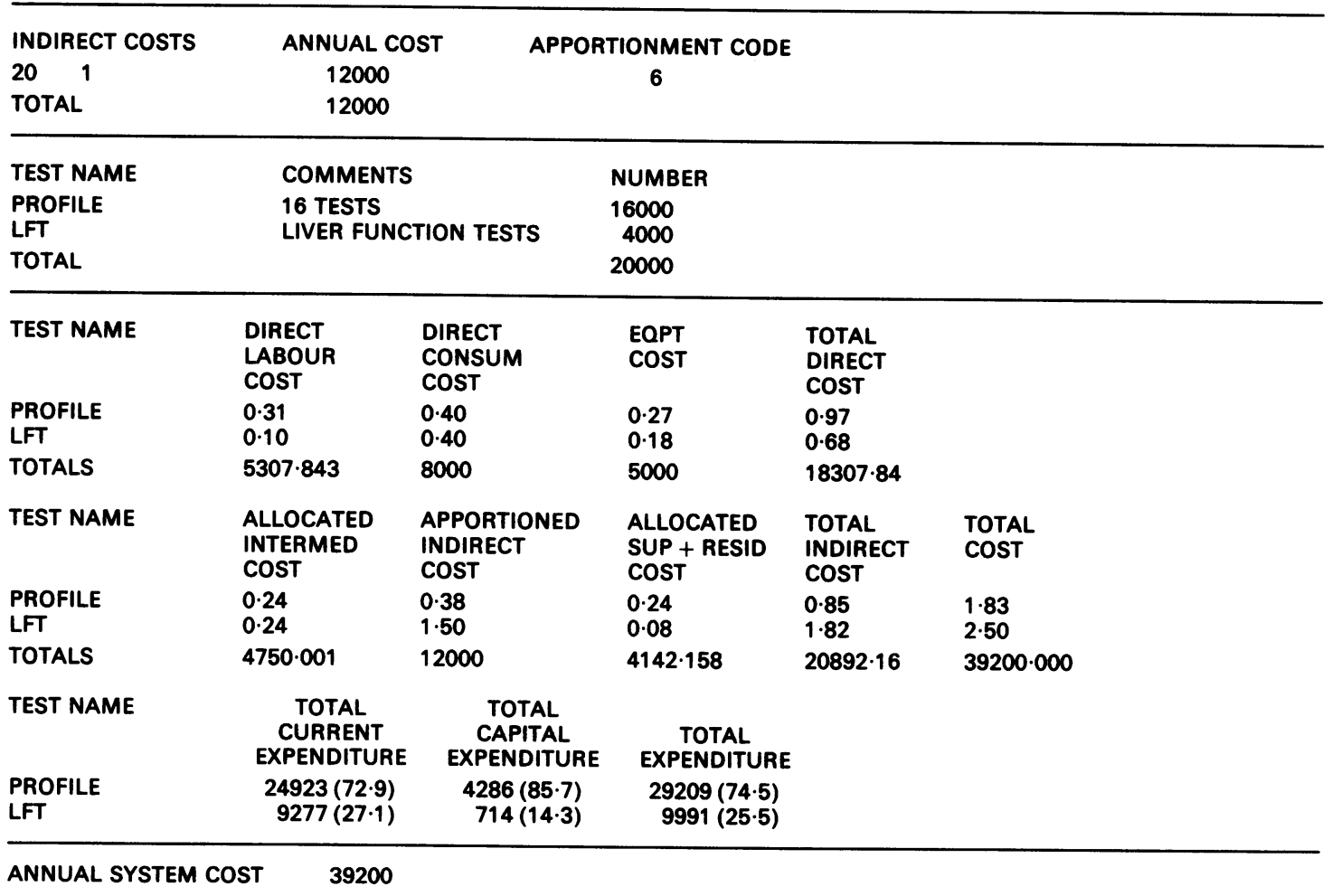

DEPARTMENTAL LABOUR REPORT

$\begin{array}{lllllllll}\text { DEPT } & \text { TOTAL } & \text { TOTAL } & \text { H-O } & \text { SUPERV } & \text { SUP } & \text { SUP } & \text { RESID } & \begin{array}{l}\text { RES } \\ \text { NO }\end{array} \\ \text { TESTS } & \begin{array}{l}\text { LABOUR } \\ \text { COST }\end{array} & \begin{array}{l}\text { AT } \\ \text { WSS }\end{array} & \begin{array}{l}\text { AT } \\ \text { WSS }\end{array} & \begin{array}{l}\text { AT } \\ \text { SECS }\end{array} & \begin{array}{l}\text { AT } \\ \text { DEPT }\end{array} & \begin{array}{l}\text { AT } \\ \text { SECS }\end{array} & \begin{array}{l}\text { AT } \\ \text { DEPT }\end{array} \\ 100 & 20000 & 14000 & 9058 & 4000 & 0 & 0 & 942 & 0\end{array}$

SECTION LABOUR REPORT

NO TESTS TOTAL H-O

110 COST WS

H-O SUPERV SUP RESID RES

AT AT AT AT AT

$110 \quad 20000 \quad 14000 \quad 9058$

WSS SEC WSS SEC

WORKSTATION LABOUR REPORT

\begin{tabular}{|c|c|c|c|c|c|}
\hline $\begin{array}{l}\text { WORK } \\
\text { STATION } \\
\text { NO }\end{array}$ & $\begin{array}{l}\text { TOTAL } \\
\text { TESTS }\end{array}$ & $\begin{array}{l}\text { TOTAL } \\
\text { LABOUR } \\
\text { COST }\end{array}$ & $\begin{array}{l}H-O \\
\text { AT } \\
\text { WS }\end{array}$ & $\begin{array}{l}\text { SUPERV } \\
\text { AT } \\
\text { WS }\end{array}$ & $\begin{array}{l}\text { RESID } \\
\text { AT } \\
\text { WS }\end{array}$ \\
\hline $\begin{array}{l}111 \\
112\end{array}$ & $\begin{array}{r}20000 \\
0\end{array}$ & $\begin{array}{l}9450 \\
4550\end{array}$ & $\begin{array}{l}5308 \\
3750\end{array}$ & $\begin{array}{r}3200 \\
800\end{array}$ & $\begin{array}{r}942 \\
0\end{array}$ \\
\hline
\end{tabular}

Fig 7 Printout of cost analysis: (a) equipment costs; (b) list of indirect costs; (c) list of tests performed; (d) test costs, with breakdown into three direct and three indirect costs, and then total annual expenditure (current and capital) on each test, also as percentage of all tests; (e) total annual cost of laboratory; $(f)$ departmental, section (SEC), and workstation (WS) labour cost reports, each distinguishing between hands-on, supervisory, and residual labour. 
Hands-on labour cost

Supervisory labour cost

Residual labour cost.

Fig 7 shows the printout of the complete cost analysis of the illustrative example, which consists of an extremely small laboratory system containing an intermediate (preparatory) workstation plus a single workstation producing results of two tests (serum assays) and staffed by two people.

\section{Comment}

The illustrative example is artificial-for example, to show the calculations clearly the total expenditure on consumables has been set so as to equal the cost of consumables in performing the 20000 tests, so that there is no residual consumables cost. The total allocated residual cost (£4142) therefore equals the residual (£942) plus supervisory $(£ 3200)$ labour costs at workstation 111 (see workstation labour report, fig 7, lowest block). The labour costs at preparatory workstation 112 have already been allocated in the column headed "allocated intermed cost" (fig 7) and there is therefore no residual labour cost at this workstation.

The striking difference in effect of allocating intermediate, indirect, and residual costs by the three different apportionment bases-test number, test type, and test direct labour cost respectively - can be seen by examination of the values in the three "allocated cost" blocks of fig 7 .

The program is available (from JAS) as a tech- nically supported software package for use in National Health Service laboratories. It runs on all IBM and IBM compatible microcomputers.

Financial assistance from the Department of Health and Social Security (Research Management Division) for JAS is gratefully acknowledged. Discussions with Mr JA Hurst, Mr A Gault, and Mr RD Jennings, Department of Health and Social Security, and with Dr Joyce Bell and Mr A Leete, Department of Chemical Pathology, Royal Free Hospital, London, were most helpful.

\section{References}

1 Broughton PMG, Woodford FP. Benefits of costing in the clinical laboratory. J Clin Pathol 1983;36:1028-35.

2 Department of Health and Social Security. Health services management: management budgeting. $\mathrm{HN}(85) 3$. London: DHSS, 6 .

3 Tarbit IF. Costing clinical biochemistry services as part of an operational management budgeting system. $J$ Clin Pathol 1986;39:817-27.

4 Broughton PMG, Hogan TC. A new approach to the costing of clinical laboratory tests. Ann Clin Biochem 1981;18:330-42.

5 Stilwell JA. Costs of a clinical chemistry laboratory. J Clin Pathol 1981;34:587-94.

6 World Health Organisation Working Group. Assessment of benefits and costs of clinical laboratory testing. Geneva: World Health Organisation, 1984 (LAB/84.5).

7 National Hospital Productivity Improvement Program. Canadian workload measurement system: laboratory. Ottawa: Statistics Canada, 1986-1987, ISBN 0-660-52845-2 (published annually).

Requests for reprints to: Dr FP Woodford, Chief Scientific Officer, Department of Health and Social Security, 14 Russell Square, London WC1B 5EP, England. 